\title{
Regression Approaches for Hydrograph Separation: Implications for the Use of Discontinuous Electrical Conductivity Data
}

\author{
Antonia Longobardi ${ }^{1, *(\mathbb{D})}$, Paolo Villani ${ }^{1,2}{ }$, Domenico Guida ${ }^{1}$ and Albina Cuomo ${ }^{1}$ \\ 1 Department of Civil Engineering, University of Salerno, 84084 Fisciano (SA), Italy; p.villani@unisa.it (P.V.); \\ dguida@unisa.it (D.G.); acuomo@unisa.it (A.C.) \\ 2 CUGRI-InterUniversity Centre for the Prediction and Prevention of Major Hazards, \\ 84084 Fisciano (SA), Italy \\ * Correspondence: alongobardi@unisa.it; Tel.: +39-089-963408
}

Received: 6 August 2018; Accepted: 6 September 2018; Published: 13 September 2018

check for updates

\begin{abstract}
Understanding of runoff generation mechanisms affects the ability to manage streamflow quantity and quality issues. Concerning the baseflow in particular, measurements are almost never available and hydrograph separation is generally applied to characterize its relevant patterns. As an alternative to well-known recursive digital filters and mass balance filtering methods, this paper deals with the use of regression approaches, based on electrical conductivity measurements, as a proxy for total dissolved solids, to separate baseflow from total flow. Particular focus is placed on their flexibility and ability to adapt to discontinuous electrical conductivity data measurements. To illustrate this, we analyze a hydrochemical dataset collected from the Ciciriello experimental catchment (Southern Italy). The main findings are as follows: A comparative analysis suggests that the performance of regressive approaches in the case of daily electrical conductivity measurements is better than that of calibrated recursive digital filters. Weekly monitored electrical conductivity data led to performances comparable to the daily scale monitoring, and even monthly observation leads to a nonsignificant reduction in regression hydrograph filter performance; this shows how spot geochemical data monitoring may present valid and operational alternatives for characterization of baseflow in poorly gauged catchments.
\end{abstract}

Keywords: hydrograph filtering; electrical conductivity; baseflow; headwater catchment; Mediterranean climate

\section{Introduction}

Knowledge of hydrological processes is a key point in applied hydrology studies, and the understanding of runoff generation mechanisms is a milestone and, moreover, a challenging task in this field of research. In particular, reliable estimation of the baseflow process and of the low flow regime is of practical importance in the management of hydrological drought issues and in general for sustainable freshwater utilization [1-3]. Unfortunately, to characterize the low streamflow regime, direct baseflow measurements are needed, but they are almost never available; therefore, hydrograph filtering techniques are generally adopted to perform a robust and quantitative assessment of baseflow patterns from hydrographs.

Several approaches have been reported in the scientific literature for hydrograph separation purposes, but recursive digital filters and mass balance filtering methods appear to be the most attractive and effective approaches. A large number of recursive digital filters (RDFs) are grounded on the idea that baseflow is a smooth frequency component of the total hydrograph, and, then, the high-frequency signals are filtered from the low-frequency signals [4-7]. RDFs are based on 
a modelling framework that requires calibration based either on field measurements or on user experience, making the criteria subjective in the calculation. As RDFs still do not consider the hydrological phenomena behind baseflow production, they can present a persistent disagreement between the true and estimated baseflow [8]. The mass balance filtering (MBF) method is considered to be a more objective approach because it is based on basin-specific physical process response observations, recorded and stored in the relevant monitoring dataset. The MBF method appears to be an important tool, especially when investigating systems are characterized by large, nonlinear, complex connectivity and threshold-dominated processes driven either by climatic features or by the variety in runoff generation mechanism occurrences [9-11].

Based on the collection of different physical or geochemical streamflow properties, substantial attention has been given to electrical conductivity (EC), which is considered to be an easily monitored and inexpensive proxy for total dissolved solids and a signature for different water components, when the monitoring system is supported by an effective hydro-geomorphological conceptual model [9]. Such an integrated approach provides an objective and physically-based calibration for the use of RDF methods [12-16].

Beside the previously described well-known techniques for hydrograph separation, regression approaches based on the connection existing between hydrology and the solute transport within the catchment have also been considered, though they are not popularly used. The aforementioned connection reflects a relationship between solute concentration (e.g., electrical conductivity) and total catchment discharge $[17,18]$. Alternatively, regression approaches that directly link the baseflow discharge, derived by applying the MBF, to the total discharge have been further accounted for [19].

Unfortunately, reliable applications based on the use of EC data require high-frequency monitoring campaigns, which are time- and cost-consuming activities [17]. Long-term EC monitoring campaigns are indeed needed for the long-term application of MBF methods. The calibration of RDF approaches, which represents an element of great complexity, also requires long-term EC measurements, especially for particular catchment types such as catchments with a small baseflow component and extremely variable climatic conditions $[8,10]$. Although measuring EC data is today a relatively easy process, EC measurements are not commonly available outside research catchments. In some cases, regulatory authorities concerned with environmental quality do monitor geochemical data, but they often plan monthly scale monitoring surveys which are generally considered unsuitable for accurate water resource analysis. In summary, while remaining in a framework that considers the use of EC data, which makes the characterization of baseflow patterns more objective, the opportunity for a methodology based on the use of discontinuous EC data that offers a cost-benefit trade-off would be interesting from both a scientific and practical point of view.

In this context, the current paper reports on the ability of regressive approaches, based on EC data monitoring to identify the baseflow component, with particular emphasis on their flexibility and adaptability to the use of discontinuous EC data and on their ability to represent an approach capable of realistically separating the streamflow component on the basis of a parsimonious dataset. For this purpose, a hydrophysical dataset from the Ciciriello experimental catchment, which is a $3 \mathrm{~km}^{2}$ watershed located in the Cilento UNESCO Global Geopark (Southern Italy), has been analyzed [9]. Water depth, discharge, electrical conductivity, and rainfall time series are available at the daily scale from December 2012 onward and are currently ongoing.

In summary, the specific objectives of the presented research are as follows:

(1) Investigate the ability of regression approaches to identify the baseflow component, through comparison with the application of well-known recursive digital filters and MBF methods;

(2) Assess the flexibility and ability of regression approaches in identifying the baseflow pattern for discontinuous EC data monitoring. 


\section{Materials and Methods}

\subsection{The Study Site}

The Ciciriello experimental watershed $\left(40.20^{\circ} \mathrm{N} 15.54^{\circ} \mathrm{E}\right)$ is located in the southern sector of the Campania region in Southern Italy (Figure 1). The area of the watershed is approximately $3 \mathrm{~km}^{2}$, and it is a dominantly forested headwater catchment area without relevant human impacts. Elevation in the watershed ranges from 420 to $812 \mathrm{~m}$ above mean sea level. The climate of the region is humid Mediterranean. The average annual precipitation is approximately $1600 \mathrm{~mm}$, with a marked difference between the average monthly summer precipitation (approximately $30 \mathrm{~mm}$ ) and the average monthly winter precipitation (approximately $250 \mathrm{~mm}$ ). From a hydro-geomorphological point of view, the catchment mainly consists of hilly, soil-mantled, and shallow aquifers and a deep sandstone fractured aquifer. Permanent springs from the bedrock aquifer; seasonal outflows from the shallow, perched aquifers; and colluvial deposits further contribute to the stream discharge.

Since December 2012, water depth (D), discharge (Q), and electrical conductivity have been measured daily at the main monitoring station located at the outlet of the catchment (420 $\mathrm{m}$ a.s.1.). The location and timing of the monitoring activity were based on direct, detailed, multitemporal hydro-geomorphological surveys and measurements, which are oriented by the "variable source areas" concept [20] and the "hydro-geomorphic paradigm" [21]. For the current study, only data from main station have been considered.

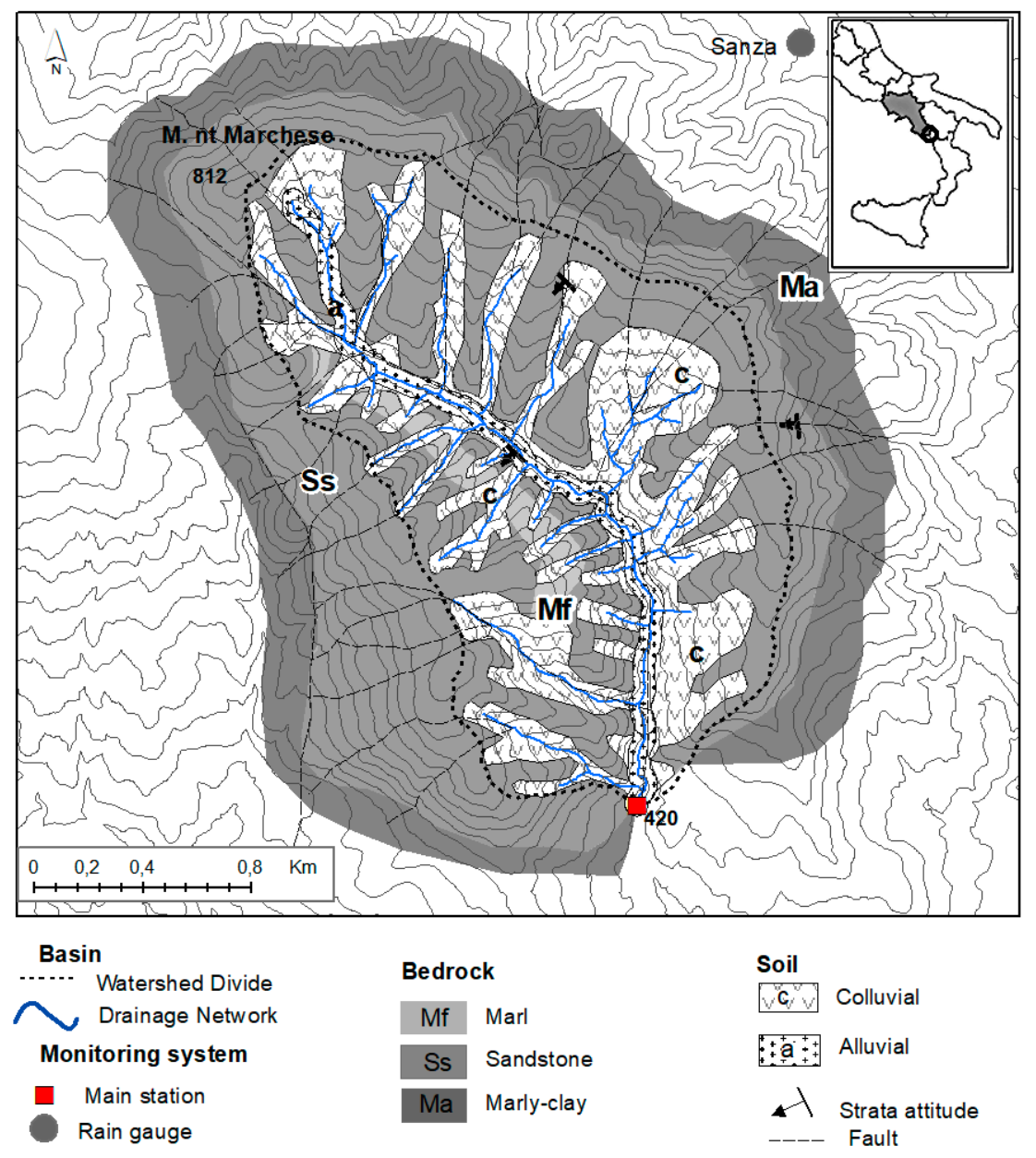

Figure 1. Schematic geological map and monitoring stations of the Ciciriello experimental catchment, Cilento UNESCO Global Geopark. 


\subsection{Hydrograph Separation by the Mass Balance Filtering Method}

The mass balance filtering method (MBF) is based on the assumption that baseflow has different chemical characteristics compared with surface runoff due to the different flow paths of these two types of flow. The total streamflow can be separated into different components on the basis of the single component concentration. This is possible by considering the following system of equations (MBF):

$$
\left\{\begin{array}{l}
Q_{t}=Q_{s f, t}+Q_{b f, t} \\
Q_{t} \cdot E C_{t}=Q_{s f, t} \cdot E C_{s f}+Q_{b f, t} \cdot E C_{b f}
\end{array}\right.
$$

where $Q$ is the total measured streamflow $(1 / \mathrm{s}) ; \mathrm{Q}_{\mathrm{sf}}$ is the surface streamflow component $(1 / \mathrm{s})$; $\mathrm{Q}_{\mathrm{bf}}$ is the baseflow component $(1 / \mathrm{s})$; EC is the measured streamflow $\mathrm{EC}(\mu \mathrm{S} / \mathrm{cm}) ; \mathrm{EC}_{\mathrm{sf}}$ is the EC surface component $(\mu \mathrm{S} / \mathrm{cm})$; ECbf is the EC baseflow component $(\mu \mathrm{S} / \mathrm{cm})$; and $\mathrm{t}$ is the time index. Then, the baseflow discharge at time $t$ is

$$
\mathrm{Q}_{\mathrm{bf}, \mathrm{t}}=\mathrm{Q}_{\mathrm{t}} \frac{\mathrm{EC}_{\mathrm{t}}-\mathrm{EC}_{\mathrm{sf}}}{\mathrm{EC}_{\mathrm{bf}}-\mathrm{EC}_{\mathrm{sf}}}
$$

Adequate long-term monitoring activity ensures the exploration of a full range of $\mathrm{EC}_{\mathrm{bf}}$ and $\mathrm{EC}_{\mathrm{sf}}$ variability [22,23]. For this case study, $\mathrm{EC}_{\mathrm{bf}}$ was assumed to be the end-member of the stream water electrical conductivity during the period with the lowest streamflow (approximately $350 \pm 10 \mu \mathrm{S} / \mathrm{cm}$ ), while $\mathrm{EC}_{\mathrm{sf}}$ was assumed to be the end-member of the stream water electrical conductivity during the highest streamflow period (approximately $80 \mu \mathrm{S} / \mathrm{cm}$ ). The almost constant values used as end-members for the surface streamflow and baseflow components were validated via an analysis of the total electrical conductivity and discharge dataset collected for the Ciciriello catchment, which was recorded for different temporal intervals (daily, weekly, and monthly) and at different control points (main, secondary, spring, riparian corridor, and colluvial hollow stations) that were distributed within the catchment [9].

The baseflow pattern derived by the application of the MBF method, for purpose of comparison, is considered in the following applications as the observed baseflow pattern.

\subsection{Hydrograph Separation by Digital Filters}

Lyne and Hollick [4] proposed a low-pass filter that separates the total streamflow signal into a high-frequency component (runoff) and a low-frequency component (baseflow). The filter equation is written as

$$
\mathrm{Q}_{\mathrm{bf}, \mathrm{t}}=\mathrm{aQ}_{\mathrm{bf}, \mathrm{t}-1}+\frac{1-\mathrm{a}}{2}\left(\mathrm{Q}_{\mathrm{t}}-\mathrm{Q}_{\mathrm{t}-1}\right)
$$

subject to the condition $\mathrm{Q}_{\mathrm{bf}, \mathrm{t}} \leq \mathrm{Q}_{\mathrm{t}}$, where $a$ is the filter parameter, which is subject to calibration in order to provide a reliable hydrograph filtering. The one-parameter filter has to be applied in a recursive algorithm, which balances the number of passes by the filter with the value of the filter parameter. A total of three passes were used in this study, as an even number of passes would minimize the signal phase distortion [24].

The Eckhardt filter algorithm [5] has been demonstrated as a flexible method, and a number of one-parameter filters reported in the applicable literature are all special cases of the two-parameter Eckhardt filter. The baseflow component can be considered as

$$
\mathrm{Q}_{\mathrm{bf}, \mathrm{t}}=\alpha \mathrm{Q}_{\mathrm{bf}, \mathrm{t}-1}+\beta \mathrm{Q}_{\mathrm{t}}
$$

which is subject to the restriction $\mathrm{Q}_{\mathrm{bft}} \leq \mathrm{Q}_{\mathrm{t}}$. Assuming a linear relation between the outflow from the aquifer and its storage, parameters $\alpha$ and $\beta$ in Equation (4) can be expressed as functions of 
the recession constant $a$ and a second parameter, $\mathrm{BFI}_{\max }$ (the maximum BFI value of the algorithm). The following expression then holds:

$$
\mathrm{Q}_{\mathrm{bf}, \mathrm{t}}=\frac{\left(1-\mathrm{BFI}_{\max }\right) \mathrm{a} \mathrm{Q}_{\mathrm{bf}, \mathrm{t}-1}+(1-\mathrm{a}) \mathrm{BFI}_{\max } \mathrm{Q}_{\mathrm{t}}}{1-\mathrm{aBFI}_{\max }}
$$

which is subject to the restriction $\mathrm{Q}_{\mathrm{bf}}, \mathrm{t} \leq \mathrm{Q}_{\mathrm{t}}$. While parameter $a$ can be estimated by a recession analysis, there is no objective way to define $\mathrm{BFI}_{\max }$, which is initially introduced as a predefined parameter depending on the geological and hydrogeological catchment properties. The assessment of the $\mathrm{BFI}_{\max }$ value represents the most critical step in the filter application, and the origin of the filter also suggests the coupled use of different methods, such as a tracer experiment, to optimize the $\mathrm{BFI}_{\max }$ parameter settings $[5,25]$.

\subsection{Hydrograph Separation by Regression Approaches}

A connection exists between hydrology and the solute transport within a catchment, which reflects the relationship between the total solute concentration and the catchment discharge. In a natural, non-arid, nonglaciated and nonevaporative aquifer-supported catchment, typical concentration versus discharge relationships show a reduction in major base cations and silica content with an increase in discharge values [26]. Although it is difficult to find generalized models to represent the typical form of the concentration-discharge relationship, they frequently exhibit a power-law equation [26].

The relationship between daily scale electrical conductivity and discharge data at the Ciciriello catchment is represented in Figure 2.

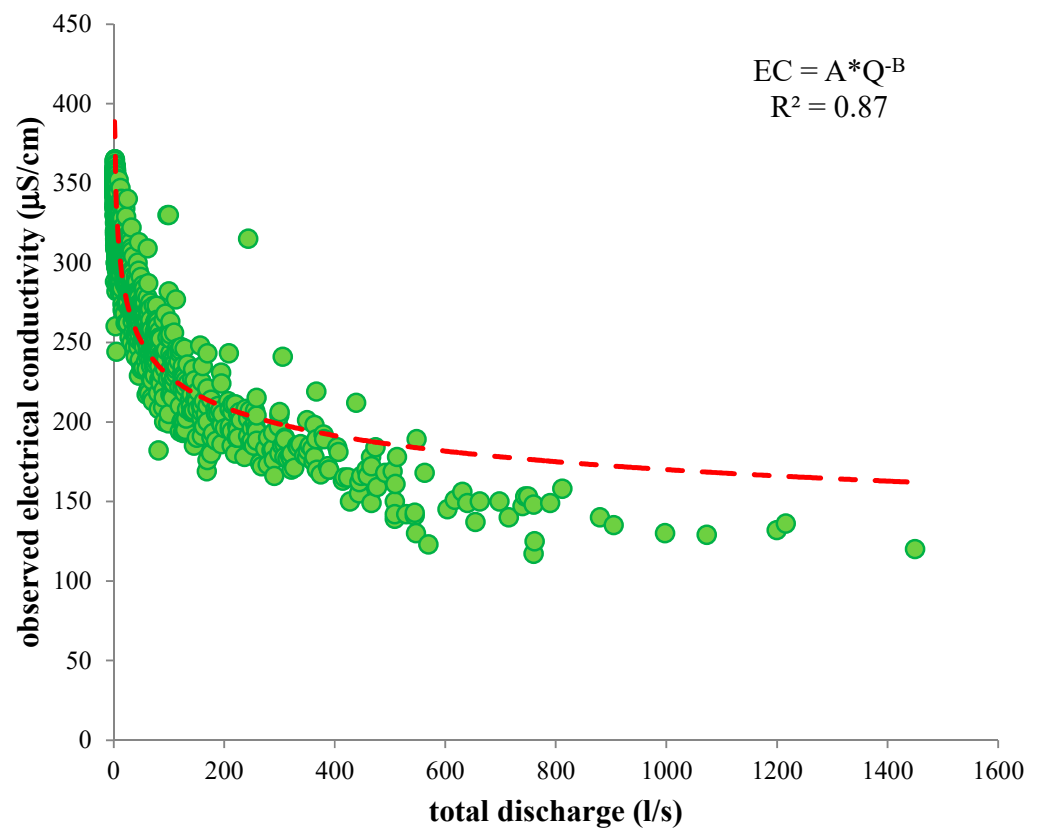

Figure 2. Relationship between total discharge and electrical conductivity monitored at the daily scale for the Ciciriello catchment.

By confirming the general results, a power law equation best fits the empirical relationship:

$$
\mathrm{EC}_{\mathrm{t}}=\mathrm{AQ}_{\mathrm{t}}^{-\mathrm{B}}
$$

After the estimation of the parameters A and B based on the observed time series, Equation (6) can then be used to model EC values as a function of the total streamflow $Q$. The modelled EC values can be then used in the application of the MBF method (Equation (2)) to finally obtain the values of $\mathrm{Q}_{\mathrm{bf}}$. This regression approach is identified as the (Q-EC) regr $_{\text {method. }}$ 
If the analytical relationship found between the observed EC and the total streamflow $Q$ is coupled with the MBF application, a functional relationship can be found between the baseflow $\mathrm{Q}_{\mathrm{bf}}$ and the total streamflow Q. In fact, by substituting Equation (6) into Equation (2), we get

$$
\mathrm{Q}_{\mathrm{bf}, \mathrm{t}}=\frac{1}{\mathrm{EC}_{\mathrm{bf}}-\mathrm{EC}_{\mathrm{sf}}}\left[\mathrm{A} \cdot \mathrm{Q}_{\mathrm{t}}^{\mathrm{B}+1}-\mathrm{Q}_{\mathrm{t}} \cdot \mathrm{EC}_{\mathrm{sf}}\right]
$$

As will be later shown, for this particular case study, the term $A \cdot Q_{t}{ }^{B+1}$ is much greater than $\mathrm{Q}_{\mathrm{t}} \cdot \mathrm{EC}_{\mathrm{sf}}\left(\mathrm{A}>>\mathrm{EC}_{\mathrm{sf}}\right)$, and Equation (7) can be further simplified to obtain

$$
\mathrm{Q}_{\mathrm{bf}, \mathrm{t}}=\frac{\mathrm{A}}{\mathrm{EC}_{\mathrm{bf}}-\mathrm{EC}_{\mathrm{sf}}} \mathrm{Q}_{\mathrm{t}}^{\mathrm{B}+1}=\mathrm{C} \cdot \mathrm{Q}_{\mathrm{t}}^{\mathrm{D}}
$$

which represents the relationship of total streamflow $Q$ versus solute concentration, which for the Ciciriello catchment assumes the shape illustrated in Figure 3. The power-law curve can be used, after the parameters $C$ and Dare estimated, to directly derive $\mathrm{Q}_{\mathrm{bf}}$ from $\mathrm{Q}$ observations. This regression approach is identified as the $\left(\mathrm{Q}-\mathrm{Q}_{\mathrm{b}}\right)_{\text {regr }}$ method.

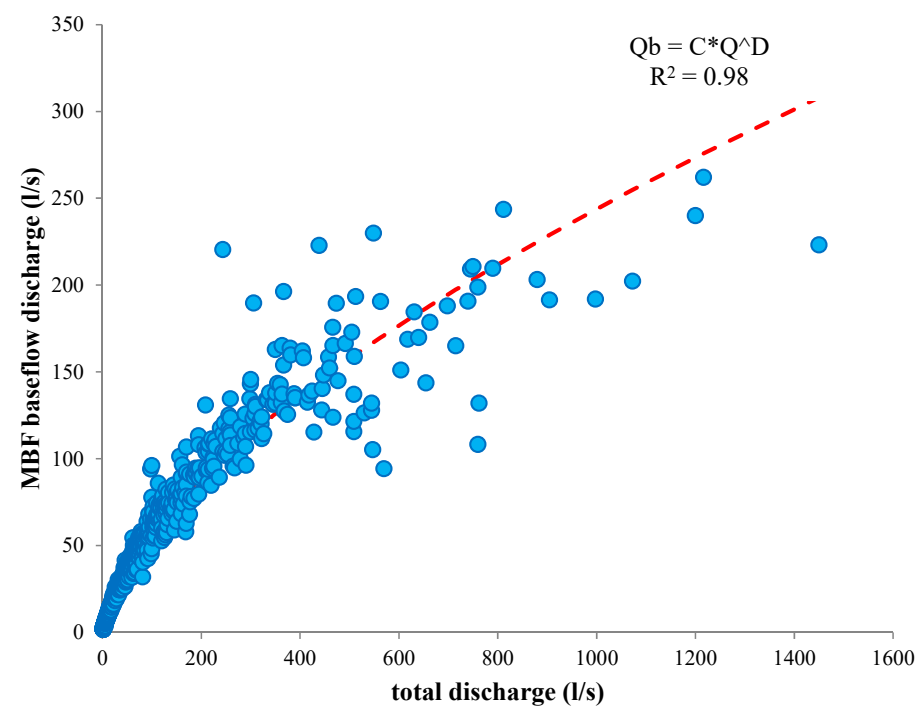

Figure 3. Relationship between total discharge and baseflow discharge derived by the application of the mass balance filtering (MBF) method at the daily scale, for the Ciciriello catchment.

\subsection{Baseflow Filter Evaluation}

The four methods previously introduced are summarized in Table 1. For the Lyne and Hollick and the Eckhardt filters, both uncalibrated and calibrated applications will be reported, where the calibration, as later shown, was provided by comparison with the baseflow pattern derived by the MBF application, considered to be the observed baseflow pattern. The regression approaches represent inherently calibrated methodologies.

Table 1. Baseflow separation methods used in the current study.

\begin{tabular}{ccc}
\hline Name & Equation & Source \\
\hline Lyne and Hollick & $\mathrm{Q}_{\mathrm{bf}, \mathrm{t}}=\mathrm{aQ}_{\mathrm{bf}, \mathrm{t}-1}+\frac{1-\mathrm{a}}{2}\left(\mathrm{Q}_{\mathrm{t}}-\mathrm{Q}_{\mathrm{t}-1}\right)$ & Lyne and Hollick [4] \\
Eckhardt & $\mathrm{Q}_{\mathrm{bf}, \mathrm{t}}=\frac{\left(1-\mathrm{BFI}_{\max }\right) \mathrm{aQ}_{\mathrm{bf}, \mathrm{t}-1}+(1-\mathrm{a}) \mathrm{BFI}_{\max } \mathrm{Q}_{\mathrm{t}}}{1-\mathrm{aBFI} \max }$ & Eckhardt [6] \\
$(\mathrm{Q}-\mathrm{EC})_{\text {regr }}$ & $\mathrm{EC}_{\mathrm{t}}=\mathrm{AQ}_{\mathrm{t}}-\mathrm{B}$ & proposed in this study \\
$\left(\mathrm{Q}-\mathrm{Q}_{\mathrm{b}}\right)_{\text {regr }}$ & $\mathrm{Q}_{\mathrm{bf}, \mathrm{t}}(\mathrm{t})=\mathrm{C} \cdot \mathrm{Q}_{\mathrm{t}}^{\mathrm{D}}$ & proposed in this study \\
\hline
\end{tabular}


The baseflow patterns derived by the application of the different separation algorithms listed in Table 1 were compared with the results from the application of the MBF method based on observed daily EC and Q records, considered as the observed baseflow. The modelled and observed baseflow were compared initially in terms of main baseflow statistical indices, such as the minimum, maximum, and average values. For each statistical index, the percentage error was computed between the observed and modelled baseflow according to the following:

$$
\text { percentage error }(\%)=100 \times\left(\frac{\text { index }_{\text {obs }}-\text { index }_{\text {mod }}}{\text { index }_{\text {obs }}}\right)
$$

Additionally, the modelled and observed baseflow were further compared in terms of the main goodness-of-fit indices, such as the root-mean-square error (RMSE), Nash-Sutcliffe efficiency coefficient (NSE), and bias (BIAS), via the following equations:

$$
\begin{gathered}
\text { RMSE }=\left[\frac{1}{n} \sum_{\mathrm{i}=1}^{\mathrm{n}}\left(\mathrm{Q}_{\mathrm{bf}, \mathrm{mod}, \mathrm{i}}-\mathrm{Q}_{\mathrm{bf}, \mathrm{obs}, \mathrm{i}}\right)^{2}\right]^{1 / 2} \\
\mathrm{NSE}=1-\frac{\sum_{\mathrm{i}=1}^{\mathrm{n}}\left(\mathrm{Q}_{\mathrm{bf}, \mathrm{obs}, \mathrm{i}}-\mathrm{Q}_{\mathrm{bf}, \mathrm{mod}, \mathrm{i}}\right)^{2}}{\sum_{\mathrm{i}=1}^{\mathrm{n}}\left(\mathrm{Q}_{\mathrm{bf}, \mathrm{obs}, \mathrm{i}}-\overline{\mathrm{Q}}_{\mathrm{bf}, \mathrm{obs}}\right)^{2}} \\
\operatorname{BIAS}(\%)=\frac{\sum_{\mathrm{i}=1}^{\mathrm{n}}\left(\mathrm{Q}_{\mathrm{bf}, \mathrm{mod}, \mathrm{i}}-\mathrm{Q}_{\mathrm{bf}, \mathrm{obs}, \mathrm{i}}\right)}{\sum_{\mathrm{i}=1}^{\mathrm{n}} \mathrm{Q}_{\mathrm{bf}, \mathrm{obs}, \mathrm{i}}} * 100
\end{gathered}
$$

\section{Results}

\subsection{Comparison Between Digital Filter' and Regression Approaches' Performances}

Four calendar years, from January 2013 to December 2016, of daily Q and EC data time series were used to evaluate the performances of each of the approaches reported in Table 1 in modelling the baseflow pattern.

In the case of the Lyne and Hollick (one parameter) and Eckhardt (two parameters) filters, both uncalibrated and calibrated applications were provided. For the uncalibrated simulation, the model parameter values suggested by the origin of the filters were used. For the one-parameter filter, $a$ was set to 0.925 based on a suggestion by Nathan and McMahon [5]. For the two-parameter filter, $a$ was set to 0.96 as a result of the recession analysis performed for the investigated catchment detailed in Longobardi et al [10], whereas the $\mathrm{BFI}_{\max }$ parameter was set to 0.25 , as suggested by the origin of the filters for a class of perennial streams with hard rock aquifers.

The BFI index, defined as the ratio between the baseflow and total streamflow value, was used for the purpose of recursive digital filter calibration. For the calibrated application, filter parameter calibration was accomplished by trial and error by matching the BFI index computed from the filtered baseflow with the same index derived from the observed baseflow (MBF application). In the case of the Lyne and Hollick algorithm, the filter parameter $a$ was subject to calibration, resulting in a very similar value of about 0.957 . In the case of the Eckhardt filter, only the $\mathrm{BFI}_{\max }$ parameter was subject to calibration, resulting in a value of 0.47 , assuming that the $a$ coefficient was reliably assessed by a recession analysis.

In the case of the regression approaches $(\mathrm{Q}-\mathrm{EC})_{\text {regr }}$ and $\left(\mathrm{Q}-\mathrm{Q}_{\mathrm{b}}\right)_{\mathrm{regr}}$, the calibration was essential to the methods themselves. It corresponded to the regression parameters of Equations (3) and (5), where calibration of the whole period of observation was used. The results of the comparison between the four proposed methods are illustrated in Table 2. 
Table 2. Baseflow statistics percentage errors (Min, Mean and Max) and goodness-of-fit indices for the different adopted filters (errors are with regard to the MBF application).

\begin{tabular}{ccccccc}
\hline Index & $\begin{array}{c}\text { Eckhardt } \\
\text { (Uncalibrated) }\end{array}$ & $\begin{array}{c}\text { Lyne and Hollick } \\
\text { (Uncalibrated) }\end{array}$ & $\begin{array}{c}\text { Eckhardt } \\
\text { (Calibrated) }\end{array}$ & $\begin{array}{c}\text { Lyne and } \\
\text { Hollick } \\
\text { (Calibrated) }\end{array}$ & (Q-EC) regr & (Q-Q $\left._{\mathbf{b}}\right)_{\text {regr }}$ \\
\hline Min (\%) & 61 & 97 & 34 & 88 & 8 & 148 \\
Mean (\%) & 39 & 26 & -1 & 1 & 9 & 6 \\
Max (\%) & 57 & 27 & 21 & 1 & 61 & 20 \\
RMSE (1/s) & 477.14 & 189.39 & 41.25 & 56.80 & 10.01 & 67.15 \\
NSE & 0.38 & 0.49 & 0.50 & 0.52 & 0.83 & 0.93 \\
BIAS (\%) & -39.16 & -26.35 & 1.15 & -1.40 & 0.82 & 5.51 \\
\hline
\end{tabular}

As far as the recursive digital filters are concerned, the effect of noncalibration always results in a positive percentage error, which therefore leads to the underestimation of different statistical descriptive indices for the baseflow pattern. Thus, calibration (particularly for statistical indices) leads to a significant improvement in the performance of the filters. The minimum and maximum values of the baseflow have the largest prediction errors, which is also true for the calibrated algorithms. In the case of the goodness-of-fit indicators, while calibration leads to marked improvements for some indicators, such as RMSE and BIAS, an improvement is not perceptible for the observed/modelled adaptation indicators. In particular, NSE (even in the case of calibration) provides a coefficient of approximately 0.5 , indicating poor adaptation of the modelled series compared to the observed series. As an example, Figure 4 shows the comparison between the baseflow patterns derived from the different algorithms proposed in Table 1 and those modelled by the MBF application for a particular period. In addition to the statistical parameters and the performance indices, Figure 4 shows that digital recursive filters, even if calibrated, are affected by a significant underestimation of baseflow values.

In the case of the regressive approaches, for which it has been said that calibration is essential, the percentage errors are larger than those related to the calibrated filters. The (Q-EC) $)_{\text {regr }}$ method is, among all of the methods tested, the one that best describes the observed baseflow minimum value (with an error of $8 \%$ ) as it directly takes into account the observed EC values corresponding to the maximum mixing values of the two-component model. The same does not happen in the case of maximum baseflow values since, at the daily scale used for the current analysis, one is not able to observe the large variability in the EC data that occurs during high-flow events [22]. Concerning instead the goodness-of-fit indicators, the regressive approaches show a notable increase in the NSE adaptation indices (which also reach 90\%) compared with the recursive digital filters.

\subsection{Applicability and Performances of Regression Approaches in the Case of Discontinuous EC Measurement}

What has been described so far shows how the reliable use of digital recursive filters is sensitive to calibration operations and, in turn, to the existence of long-term monitoring campaigns of streamflow and electrical conductivity data. However, monitoring campaigns are rather limited both in time and space, and operational methods for the characterization and evaluation of baseflow patterns to be applied even in the case of discontinuous monitoring campaigns would represent a useful solution for this limitation and, above all, to the possibility of operating at a large regional scale.

The regressive methods proposed in this study, namely, $(\mathrm{Q}-\mathrm{EC})_{\text {regr }}$ and $\left(\mathrm{Q}-\mathrm{Q}_{\mathrm{b}}\right)_{\mathrm{regr}}$, are actually naturally suited to application in the case of discontinuous data. They are based on the possibility of calibrating the relations expressed by equations (6) and (8); for such calibration, it is not as important to have continuous data as it is to have data covering a range of variabilities for the parameters of interest (in this specific case, EC data). Once equations (6) and (8) have been calibrated, it is possible to apply them, using continuous $Q$ observations, to obtain a continuous separation of baseflow from total flow.

The performances of the methods $(\mathrm{Q}-\mathrm{EC})_{\text {regr }}$ and $\left(\mathrm{Q}-\mathrm{Q}_{\mathrm{b}}\right)_{\text {regr }}$ when using the daily scale dataset have already been shown above. For the specific purpose of showing their reliability when only discontinuous data is available, a sampling experiment for the observed $Q$ and $E C$ series was performed 
to mimic a number of fictitious monitoring campaigns. The sampling time windows were set at 7 and 30 days in order to generate discontinuous EC monitoring on a weekly and monthly basis, respectively. Those time steps are indeed frequently adopted by water regulatory authorities when planning surveys for water resource management analyses. In the case of weekly and monthly monitoring, the regressive methods are indicated as $(\mathrm{Q}-\mathrm{EC}) 7$ and $\left(\mathrm{Q}-\mathrm{Q}_{\mathrm{b}}\right) 7$ or $(\mathrm{Q}-\mathrm{EC}) 30$ and $\left(\mathrm{Q}-\mathrm{Q}_{\mathrm{b}}\right) 30$, respectively.

To show the robustness of the method with respect to the sampling scheme, a mobile sampling time window was considered which moves ahead by one day. In the case of a weekly window, 7 different sampling schemes were thus determined. In the case of a monthly window, 30 different sampling schemes were instead determined. Figure 5 shows an illustration of the weekly sampling fictitious scheme; for each fictitious sample series (\#1 to \#7), the samples of Q and EC data were used to show the specific empirical relationship. Additionally, for the same samples, the MBF method was applied to derive the $\mathrm{Q}-\mathrm{Q}_{\mathrm{bf}}$ empirical relationship for each of them.

The functional relationships derived from the fictitious weekly monitoring in Figure 5 are superimposed on those derived from daily monitoring for the sole purpose of visually illustrating how the relationships fitted on the discontinuous sampling data are well adapted to those derived from daily continuous sampling. The position of the monitoring window certainly influences the probability of sampling a narrow or broad spectrum of variability in EC and Q data. As an example, the sampling corresponding to the \#1 series in Figure 5 returns, compared with the remaining series, a wider range of minimum values for the electrical conductivity (a high-flow event of about $14001 / \mathrm{s}$ is sampled in this case). The application discussed below shows how this consideration is actually of minor importance.

Each of the empirical relationships (EC-Q) and $\left(\mathrm{Q}-\mathrm{Q}_{\mathrm{b}}\right)$ derived from the weekly and monthly fictitious sampling were adapted to Equations (6) and (8), respectively. In this way, an estimate of parameters A and B (regarding the EC-Q relationship) and C and D (regarding the Q- $Q_{b}$ relationship) can be provided for each sample window. The values assumed by the parameter pairs are shown in Figures 6 and 7. The estimated values, combined with the related confidence intervals calculated with a significance level of $5 \%$, show how the variability in the estimated parameters is in fact significantly negligible, thus causing the results obtained from discontinuous monitoring to be independent from the specific position of the sampling window (provided that the considered time window is retained).

The sampling frequency clearly impacts the value of the regression parameters. This feature seems particularly evident for parameter A of the Q-EC relationship. A appears, on average, lower in the case of the monthly sampling, resulting in a reduced slope of the Q-EC relationship, which, in turn, is caused by a smaller range of variability for sampled $Q$ compared to the case of the weekly monitoring. However, a more conceptually meaningful explanation of these peculiarities and of the variability of the regression parameters would only be possible in the potential case of a comparative study in which the proposed methodology would be applied to catchments with different properties.

Regressive methods calibrated on the basis of discontinuous EC monitoring were then used for the continuous hydrograph separation, which was then compared against the observed baseflow (i.e., the baseflow derived using $\mathrm{MBF}$ ). The relative performances were evaluated, as illustrated in the previous cases, through the quantification of statistical baseflow indices and the conventional goodness-of-fit indicators. The results are shown in Table 3. In the case of weekly (monthly) monitoring, 7 (30) different regressive models were obtained; the tables show the maximum errors that are allowed among the 7 (30) models (i.e., they return the performance indices of the model that deviate most from the observations). 


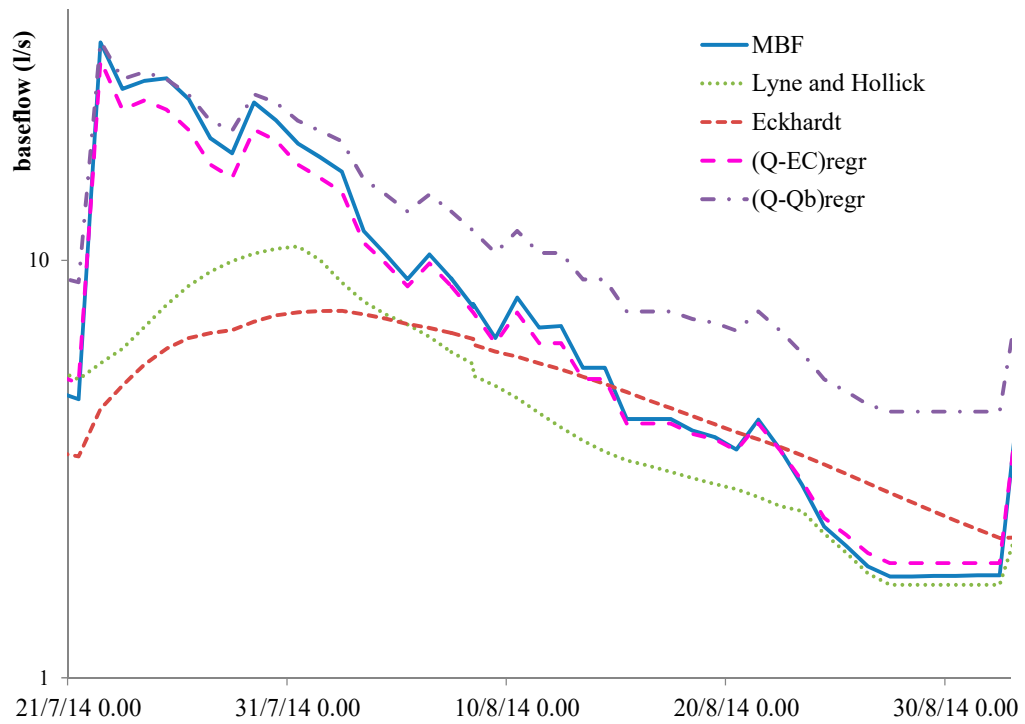

(A)

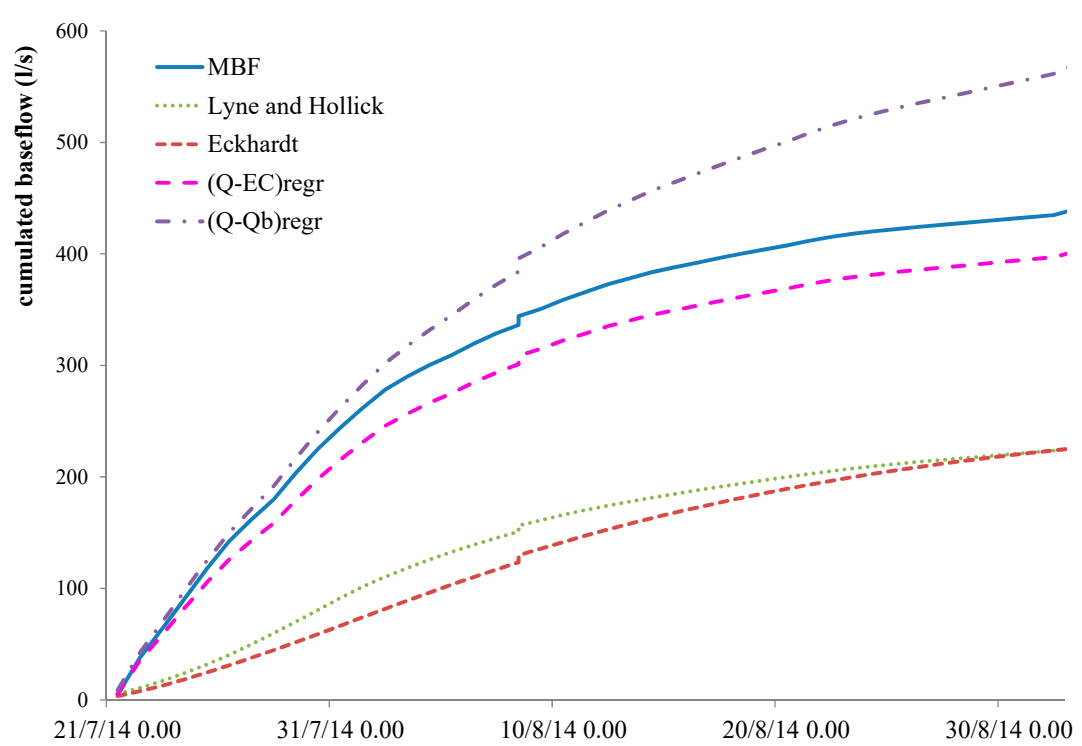

(B)

Figure 4. Comparison of baseflow patterns (A) and cumulated baseflow (B) at Ciciriello catchment, for the period from 21 July 2014 to 2 September 2014. 

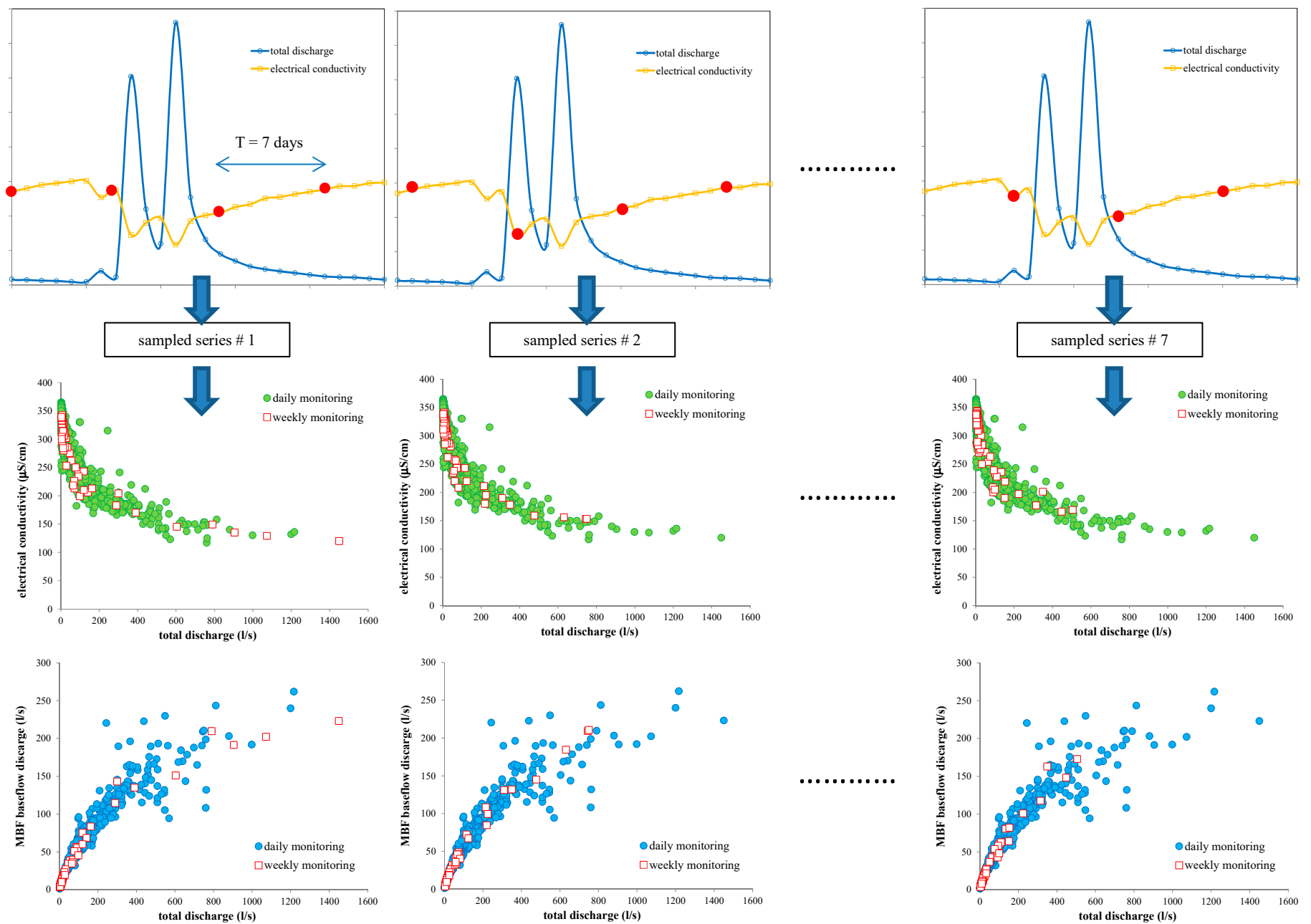

Figure 5. Fictitious weekly monitoring program. The upper panel shows total discharge and electrical conductivity patterns, and red dots represent the discontinuous monitored data. The lower panels show the associated functional relationships between EC, $\mathrm{Q}$, and $\mathrm{Q}_{\mathrm{bf}}$ derived using MBF. The weekly scale monitoring functional empirical relationships overlap the daily scale functional empirical relationships for the purpose of comparison. 

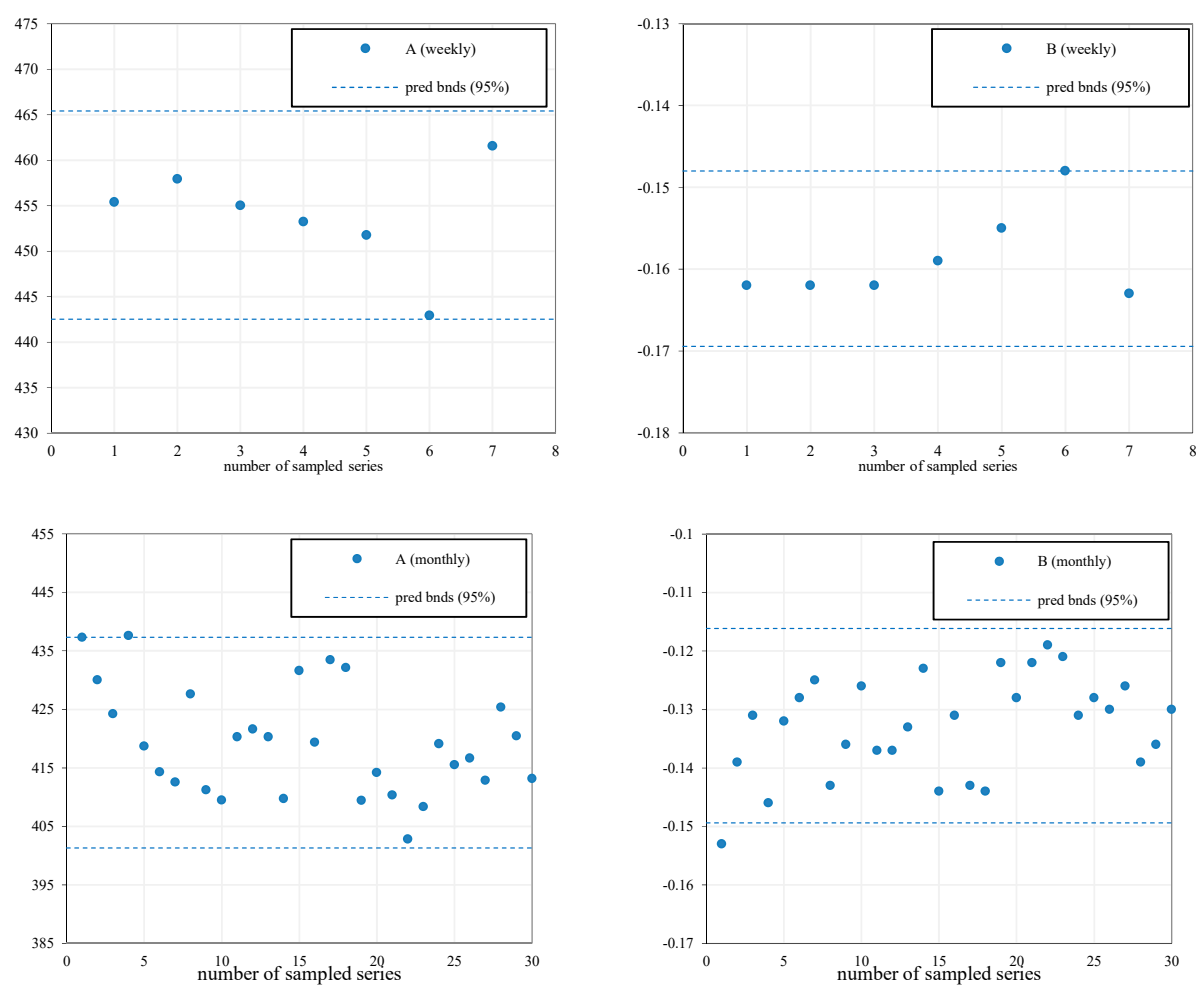

Figure 6. 95\% prediction boundaries (pred bnds) for the regression model parameters A and B in Equation (6) for the case of discontinuous measurements. The upper panel refers to a weekly monitoring program, and the lower panel refers to a monthly monitoring program.
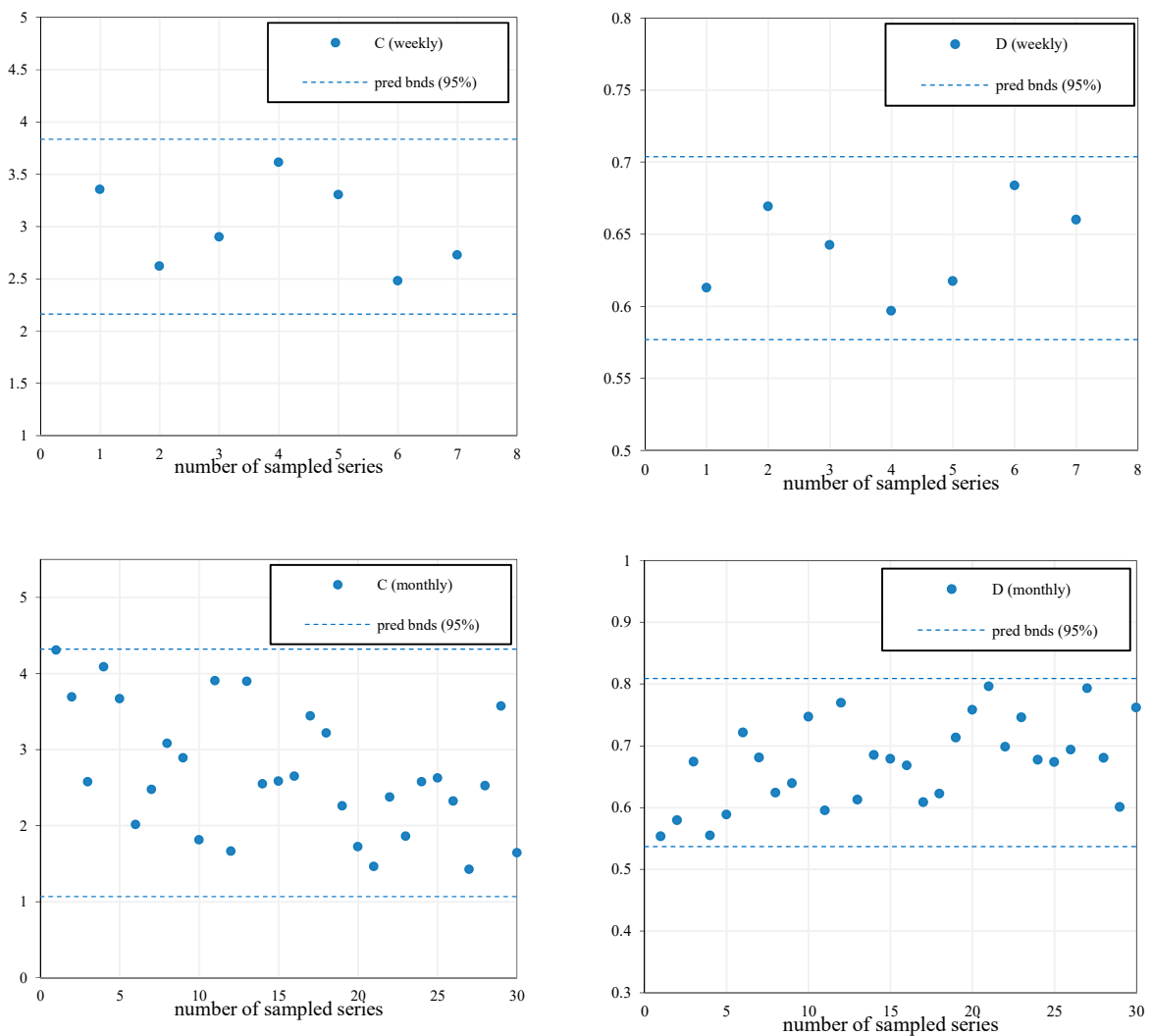

Figure 7. 95\% prediction boundaries for the regression model parameters C and D in Equation (8) for the case of discontinuous measurements. The upper panel refers to a weekly monitoring program, and the lower panel refers to a monthly monitoring program. 
Discontinuous EC monitoring at the monthly scale leads to a reduced performance in the regression models when compared to that for weekly scale monitoring, likely related to a larger variance in the fictitious monitored samples, although the reduction is not very important. EC monitoring at the weekly scale leads instead to performance indicators that are very close to those calculated for a continuous daily monitoring campaign. Even in the case of discontinuous monitoring, the differences between the methods of $(E C-Q)_{\text {regr }}$ and $\left(Q-Q_{b}\right)_{\text {regr }}$ do not appear to be substantial.

Table 3. Baseflow statistics percentage errors (Min, Mean, and Max) and goodness-of-fit indices for the regression approaches $\mathrm{Q}-\mathrm{EC}$ and $\mathrm{Q}-\mathrm{Q}_{\mathrm{b}}$ in the case of discontinuous measurements (errors are with regard to the daily scale $\mathrm{MBF}$ application).

\begin{tabular}{ccccc}
\hline Index & $(\mathbf{Q}-E C) \mathbf{7}$ & $\left(\mathbf{Q}-\mathbf{Q}_{\mathbf{b}}\right) \mathbf{7}$ & $\mathbf{( Q - E C ) 3 0}$ & $\left(\mathbf{Q}-\mathbf{Q}_{\mathbf{b}}\right) \mathbf{3 0}$ \\
\hline Min $(\mathrm{l} / \mathrm{s})$ & 25 & 181 & 20 & 227 \\
Mean $(\mathrm{l} / \mathrm{s})$ & 8 & 7 & 20 & 22 \\
regr $(\mathrm{l} / \mathrm{s})$ & 100 & 24 & 162 & 24 \\
RMSE $(1 / \mathrm{s})$ & 77.55 & 70.23 & 212.59 & 244.09 \\
NSE & 0.80 & 0.93 & 0.67 & 0.93 \\
BIAS (\%) & 6.38 & 5.77 & 17.48 & 20.07 \\
\hline
\end{tabular}

\section{Discussion and Conclusions}

Knowledge of runoff generation mechanisms affects our ability to manage streamflow quantity and quality issues. As measurements of the baseflow are almost never available, hydrograph filtering techniques are generally adopted to perform a robust quantitative assessment of baseflow patterns. The current paper reports the application of two regression approaches based on EC monitoring data, namely, $(\mathrm{Q}-\mathrm{EC})_{\text {regr }}$ and $\left(\mathrm{Q}-\mathrm{Q}_{\mathrm{b}}\right)_{\text {regr }}$, as hydrograph separation methodologies, exploring the importance of the temporal frequency of EC data on their calibration and the relative impact on their performances. An experimental dataset from the Ciciriello catchment, which is a $3 \mathrm{~km}^{2}$ watershed located in the Cilento UNESCO Global Geopark (Southern Italy), has been analyzed for this purpose.

For the studied catchment, which features extremely variable climate conditions and a nonpersistent river regime, a likely common hydro-geomorphological catchment type, it has been shown that the performances of the recursive digital filters, despite the calibration, are lower than those of regressive approaches. In fact, for the goodness-of-fit indicators, the regressive approaches show a notable increase in the NSE adaptation index, which reaches 90\% compared with the 50\% shown in the case of calibrated recursive filters, and an improvement in the prediction of minimum and average baseflow values, which cause regressive methods to be more attractive than recursive filters.

As a final result, adaptations of the analyzed regressive approaches to electrical conductivity discontinuous monitoring campaigns are suggested as valid and operational alternatives for the characterization of baseflow in poorly gauged catchments. Under fictitious monitoring campaigns, weekly sampling of EC leads to statistical performance indices similar to those obtained when using daily EC data, regardless of the particular regression equation applied.

Author Contributions: A.L., P.V., and D.G. conceived and designed the experiments; A.L. and A.C. performed the experiments and analyzed the data; all the authors contributed to writing the paper.

Funding: The APC was funded by ORSA154528 and ORSA164189 grants.

Acknowledgments: The authors gratefully acknowledge Angelo De Vita and Aniello Aloia (Cilento UNESCO Global Geopark) for their financial and logistical support in this research and Pasqualino Lovisi for the field collaboration and measurements.

Conflicts of Interest: The authors declare no conflict of interest. 


\section{References}

1. Payn, R.A.; Gooseff, M.N.; McGlynn, B.L.; Bencala, K.E.; Wondzell, S.M. Exploring changes in the spatial distribution of stream baseflow generation during a seasonal recession. Water Resour. Res. 2012, 48, W04519. [CrossRef]

2. Chiogna, G.; Skrobanek, P.; Narany, T.S.; Ludwig, R.; Stumpp, C. Effects of the 2017 drought on isotopic and geochemical gradients in the Adige catchment, Italy. Sci. Total Environ. 2018, 645, 924-936. [CrossRef] [PubMed]

3. Longobardi, A.; Van Loon, A.F. Assessing baseflow index vulnerability to variation in dry spell length for a range of catchment and climate properties. Hydrol. Process. 2018, 32, 2496-2509. [CrossRef]

4. Lyne, V.D.; Hollick, M. Stochastic time-variable rainfall runoff modelling. In Proceedings of the Hydrology and Water Resources Symposium, Perth, Australia, 10-12 September 1979; pp. 89-92.

5. Nathan, R.J.; McMahon, T.A. Evaluation of automated techniques for baseflow and recession analyses. Water Resour. Res. 1990, 26, 1465-1473. [CrossRef]

6. Eckhardt, K. How to construct recursive digital filters for baseflow separation. Hydrol. Process. 2005, 19, 507-515. [CrossRef]

7. Mei, Y.; Anagnostou, E.N. A hydrograph separation method based on information from rainfall and runoff records. J. Hydrol. 2015, 523, 636-649. [CrossRef]

8. Su, C.-H.; Costelloe, J.F.; Peterson, T.J.; Western, A.W. On the structural limitations of recursive digital filters for base flow estimation. Water Resour. Res. 2016, 52, 4745-4764. [CrossRef]

9. Cuomo, A.; Guida, D. Using hydro-chemographanalises to reveal runoff generation processes in a Mediterranean catchment. Hydrol. Process. 2016, 30, 4462-4476. [CrossRef]

10. Longobardi, A.; Villani, P.; Guida, D.; Cuomo, A. Hydro-geo-chemical streamflow analysis as a support for digital hydrograph filtering in a small, rainfall dominated, sandstone watershed. J. Hydrol. 2016, 539, 177-187. [CrossRef]

11. Stewart, M.K. 2015. Promising new baseflow separation and recession analysis methods applied to streamflow at Glendhu Catchment, New Zealand. Hydrol. Earth Syst. Sci. 2015, 19, 2587-2603. [CrossRef]

12. Zhang, R.; Li, Q.; Chow, T.L.; Li, S.; Danielescu, S. Baseflow separation in a small watershed in New Brunswick Canada, using a recursive digital filter calibrated with the conductivity mass balance method. Hydrol. Process. 2013, 27, 2659-2665. [CrossRef]

13. Cartwright, I.; Gilfedder, B.; Hofmann, H. Contrasts between estimates of baseflow help discern multiple sources of water contributing to rivers. Hydrol. Earth Syst. Sci. 2014, 18, 5-30. [CrossRef]

14. Longobardi, A.; Guida, D.; Cuomo, A.; Villani, P. At which time step do we need to monitor the stream hydro-chemistry properties for low flow characterization? Rend. Online Soc. Geol. Ital. 2015, 35, 188-191. [CrossRef]

15. Lott, D.A.; Stewart, M.T. Base flow separation: A comparison of analytical and mass balance methods. J. Hydrol. 2016, 535, 525-533. [CrossRef]

16. Saraiva Okello, A.M.L.; Uhlenbrook, S.; Jewitt, G.P.W.; Masih, I.; Riddell, E.S.; Van der Zaag, P. Hydrograph separation using tracers and digital filters to quantify runoff components in a semi-arid mesoscale catchment. Hydrol. Process. 2018, 32, 1334-1350. [CrossRef]

17. Genereux, D.P.; Jordan, M.T.; Carbonell, D. A pired-watershed budget study to quantify interbasin groundwater flow in a lowland rain forest. Costa Rica. Water Resour. Res. 2005, 41, W04011. [CrossRef]

18. Miller, M.P.; Johnson, H.M.; Susong, D.D.; Wolock, D.M. A new approach for continuous estimation of baseflow using discrete water quality data: Method description and comparison with baseflow estimates from two existing approaches. J. Hydrol. 2015, 522, 203-210. [CrossRef]

19. Lott, D.A.; Stewart, M.T. A Power Function Method for Estimating BaseFlow. Groundwater 2013, 51, $442-451$.

20. Hewlett, J.D.; Hibbert, A.R. Factors affecting the response of small watersheds to precipitation in humid areas. For. Hydrol. 1967, 1, 275-290.

21. Sidle, R.C.; Tsuboyama, Y.; Noguchi, S.; Hosoda, I.; Fujieda, M.; Shimizu, T. Stormflow generation in steep forested headwaters: A linked hydrogeomorphic paradigm. Hydrol. Process. 2000, 14, 369-385. [CrossRef]

22. Stewart, M.; Cimino, J.; Ross, M. Calibration of Base Flow Separation Methods with Streamflow Conductivity. Groundwater 2007, 45, 17-27. [CrossRef] [PubMed] 
23. Li, Q.; Xing, Z.; Danielescu, S.; Li, S.; Jiang, Y.; Meng, F.R. Data requirements for using combined conductivity mass balance and recursive digital filter method to estimate groundwater recharge in a small watershed, New Brunswick, Canada. J. Hydrol. 2014, 511, 658-664. [CrossRef]

24. Spongberg, M.E. Spectral analysis of baseflow separation with digital filters. Water Resour. Res. 2000, 36, 745-752. [CrossRef]

25. Zhang, J.; Zhang, Y.; Song, J.; Cheng, L. Evaluating relative merits of four baseflow separation methods in Eastern Australia. J. Hydrol. 2017, 549, 252-263. [CrossRef]

26. Godsey, S.E.; Kirchner, J.W.; Clow, D.W. Concentration-discharge relationships reflect chemostatic characteristics of US catchments. Hydrol. Process. 2009, 23, 1844-1864. [CrossRef]

2018 by the authors. Licensee MDPI, Basel, Switzerland. This article is an open access article distributed under the terms and conditions of the Creative Commons Attribution (CC BY) license (http://creativecommons.org/licenses/by/4.0/). 